\title{
Replacing congenitally absent teeth with implants: the importance of orthodontic preparation
}

\author{
H. BUATOIS
}

\begin{abstract}
The use of implants to replace congenitally missing teeth is a-predictable esthetic Solution that is, paradoxically less invasive than the traditional reliance on bridges to supply the missing elements because it demands little or no sacrifice of dental tissue. But this noble goal cannot be achieved unless we can assure prospective patients that the results will be stable and esthetically satisfying over the long term. This is an issue of primordial importance in view of the tender age of the patients that are the usual candidates for this treatment modality for agenesis. And no such assurance can be proffered unless we deal with the problem in a multi-disciplinary fashion from the very outset of treatment planning. We must evaluate the space needed for a replacement not just from the standpoint of the prosthetic requirements alone but also with an assessment of the associated osseous and gingival tissues in the framework of a tri-dimensional implant placement.
\end{abstract}

\section{KEYWORDS}

\author{
Agenesis \\ Congenital absence \\ Esthetics \\ Implant prosthetics \\ Treatment plan.
}




\section{1 - INTRODUCTION}

Implants, which have beeome a reliable therapeutic option for treating patients who are missing one or more teeth as well as those who are completely edentulous ${ }^{20}$, have been in clinical use for a long enough period for us to assure our patients that this alternative enjoys a rate of success, or long term prosthetic survival, that is often superior to that of traditional prosthesis. As a result, replacement of single missing teeth is now the most frequent indication for which implants are selected, not the completely edentulous cases that were the primary indication for their use 20 years ago.

The widespread demonstration of the reliability of osteointegration has made it possible for practitioners to go beyond focusing on the osseous success of implants and begin con- centrating on the esthetic and functional integration of this new modality as the primary challenge they must meet. So today practitioners select the implant option only if they are confident the final result will be at least similar to, if not better, functionally and esthetically than what could be obtained with traditional prosthetic techniques. If this assurance cannot be made implants should not be the therapy of choice (fig. 1 to 4). In other words, in implantology the debate no longerfocuses on the potential for osteointegration but rather on the quality of the results that can be proposed to patients. Because implants are biologically and structurally different from teeth, soft tissues react to them differently but patients have a right to expect esthetic outcomes similar to those seen with natural

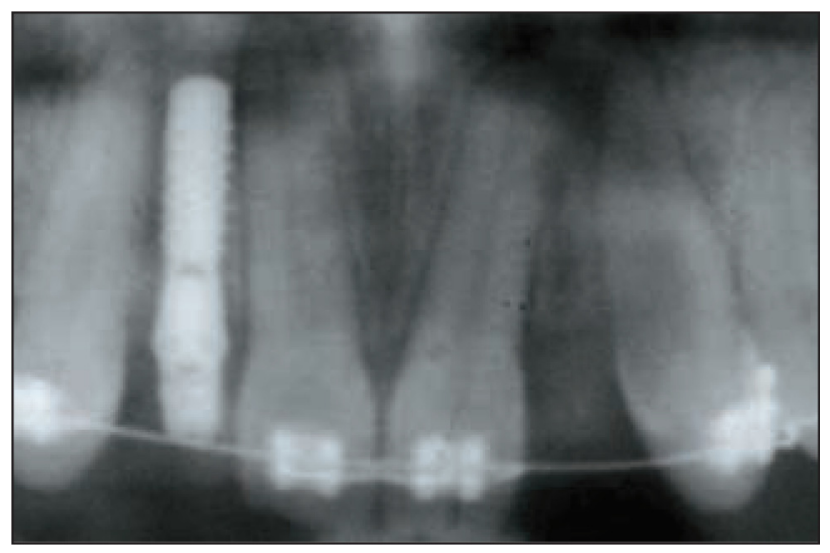

Figure 1

There was enough available space in the site of the upper right lateral incisor for us to place a narrow $3.3 \mathrm{~mm}$ diameter Straumann NNI. But in the site for the upper left lateral incisor the convergence of the roots of the upper left central incisor and the upper left canine had compromised the optimal placement of an implant. This is an illustration of a case where the prosthetic spaces for the missing upper laterals are symmetrica! and sufficient to support replacements mechanically but not adequate for biological and esthetic integration of an implant in the left lateral area because of the absence of a column of bone at least $6.5 \mathrm{~mm}$ wide. This occurred because of migrations of neighboring roots into space of agenesis whose amplitude cannot be corrected. 


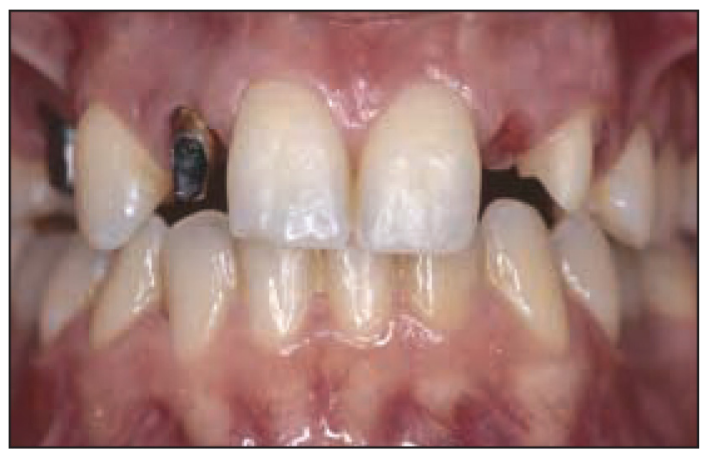

Figure 2

The treatment plan called for the restoration of the upper right lateral with a ceramo-metallic crown placed on a Straumann titanium implant. The upper left lateral will be replace with a ceramo-metallic supported on the prepared vital left caninefinished with a ceramic shoulder. The pontic in the lateral site will be shaped to prepare the emergence bed of the crown.

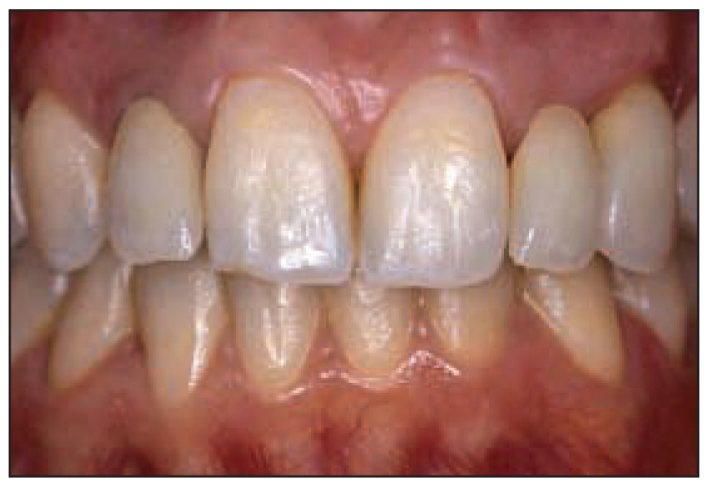

\section{Figure 3}

The prosthesis the day it was set in place. We had succeeded in making the amount of soft tissues and hard tissues in the two sites symmetrical by selecting the correct replacement options for both. But it would take another six months for the gingiva to adapt itself correctly around the pontic.

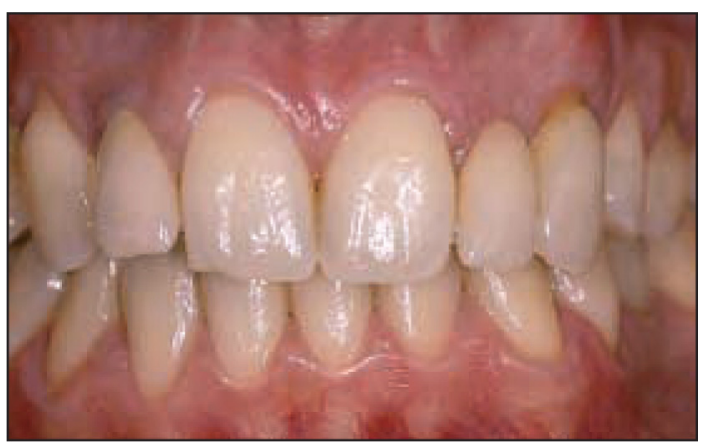

\section{Figure 4}

The situation has remained stable 3 years after treatment.

teeth. So dentists must re-create harmony in size and shape of the clinical crown but also in the implant's supporting tissues ${ }^{2,13,19}$. Practitioners who provide implants for patients cannot consider they have achieved a succcessful result the day of the prothesis delivery but have to understand that this is only a first step in a process that must conclude with the implant's satisfactory biological inte- gration with its surrounding periodontal environment ${ }^{3}$. It is the accumulated experience with previous esthetic treatments that impels us along this evolution leading to implantology's full maturity. This notion is most fully expressed in the treatment of congenitally missing teeth. This procedure requires us to propose to young patients a treatment in which the notions of esthetic 
integration, durability, and stability are the cornerstones of a successful outcome. We must obtain success in orthodontic treatments in which patients and their parents have made substantial investments not only financially but also emotionally. This means, of course, that it is essential for the inter-disciplinary team be well aware of their own responsibilities and those of the other participants in understanding the dental milieu required for obtaining a result that is satisfactorily integrated biologically and esthetically. In treating congeni- tally missing teeth orthodontists should have over-all objectives clearly in mind.

They can deal with different options as to close the space or to open and maintain it so an tooth bud transplantation can be done during the treatment or an implant can be placed after the treatment.

Even though orthodontically the site might appear quite suitable for space opening, the implantologist may view it as inadequate for supporting an esthetically satisfying implant.

\section{2 - SOME SPECIFIC ASPECTS OF SITES OF AGENESIS}

We can speak of a minimal or maximal space prosthetic space, but this notion is simplistic because it is limited to the mechanical dimension. Looking at the problem from the viewpoint of an implantologist, it is preferable to think of the space in at least three dimensions: the biological for its periodontal health, the osseous for its future stability, and the prosthetic for its dimensional relationship with neighboring teeth. These considerations become functional, of course, only after the removal of orthodontic appliances. Therefore it is vitally important that the orthodontist and the implantologist establish a working agreement about what the needs and what the former can actually accomplish (fig. 7 to 11).

The sites in the arch where teeth are congenitally absent have certain specific aspects:
- they are spaces where temporary teeth will be replaced by a prosthesis simulating permanent teeth. There will be, accordingly, a discrepancy in localized arch length. Either the available space will be too small for incisors and canines or too large for second premolars;

- the absence of permanent tooth buds and the osseous stimulation they incite will have caused a variable amount of insufficiency in the supporting bone depending of the periodontal phenotype;

- the teeth adjacent to the agenesis site where no root formation is taking place will have tilted into the space thus made available;

- an osseous crest without scalloped design usual with the localized edentulous arch, associated with a bone vertical excess compare to the ideal profile. 


\section{3 - COMPENSATIONS}

Practitioners prepare an assessment of the prosthetic requirements in bone and gingival that apply to the space to be provided with a replacement dental unit. The implant-prosthetic treatment plan should take into account the fundamental differences between an implant and a natural tooth. The neck of an implant, for example, is flat while a natural tooth has a line marking the cement-enamel junction that takes a scalloped shape particularly marked in the anterior region. When sectioned an implant will appear circular while sections of natural teeth are far from circular (fig. 5 and 6). In order to be successful the implant treatment must find a way to circumvent this difference. To accomplish this, three types of compensation are available:

- osseous compensations;

- gingival compensations;

- prosthetic compensations.

It is important for practitioners to remember that the more effective the osseous compensation is, and with it the bone volume, the less considerable will gingival, and with them, prosthetic adjustments, have to be. Accomplished successfully, in this order of chronology, these adjustments will encourage periodontal stability. And, conversely, overcompensation gingivally and prosthetically because of an osseous deficiency, will lead to periodontal instability. Determining adequate implant space, therefore, requires an analysis of the amount of bone available in relation to the size of the prosthetic replacement. This osseous volume should be enough to allow for placement of an implant whose shape will encourage periodontal stability vertically as well as horizontally (fig. 7 to 12). What we are talking about is the correct three dimensional positioning of an implant as the Third Conference Consensus of the International Team of Implantology defined it $^{1,6}$.

\section{4 - THREE-DIMENSIONAL POSITIONING}

In the mesio-distal sense we have defined two proximal columns that delineate the danger zones into which the implants should not trespass, in effect a distance of $1.5 \mathrm{~mm}$. This prohibition is a result of the shape of he implant neck that cannot follow the periodontal festoon path of a natural tooth. For the neck of an implant to be correctly placed buccaly, its smooth sector, or the the implant plateform must definitely set below the crest of the bone in the proximal area. Tarnow et $a^{23}$ have shown that under the 1.5 "no contact" zone between the neck of the implant and adjacent natural teeth practitioners have to take into consideration probable resorption of the tooth's proximal bone. This will lead to a vertical loss of the bone 

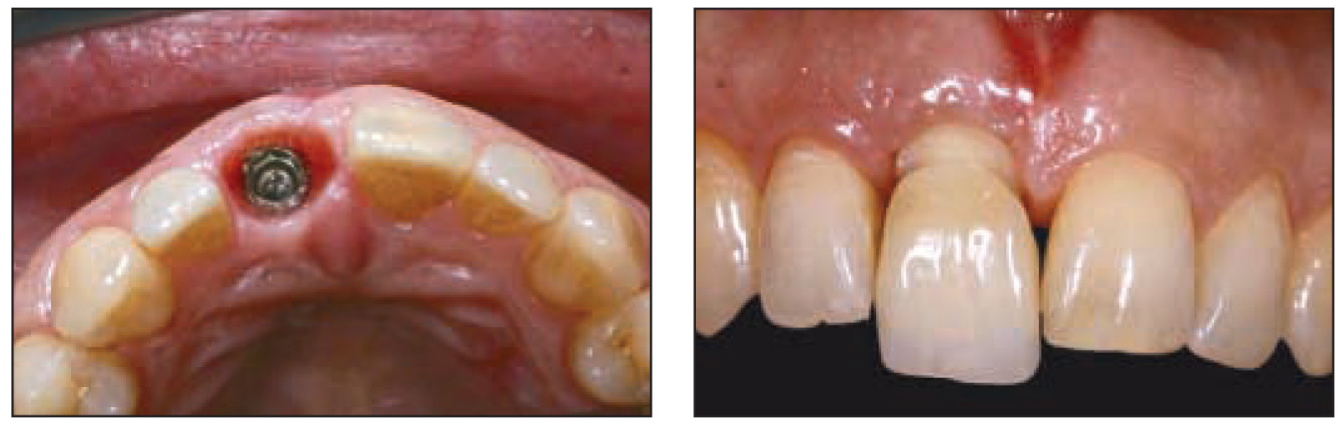

Figures 5 and 6

Anatomy of the neck of the implant (Straumann RN) contrasts with the emergence profile of the tooth placed in the gingiva around the prosthetic post and the provisional crown. It is the quality of the available bone volume supporting the amount of gingiva that is, itself, the necessary support for the long term emergence profile that is stable and esthetically satisfactory.

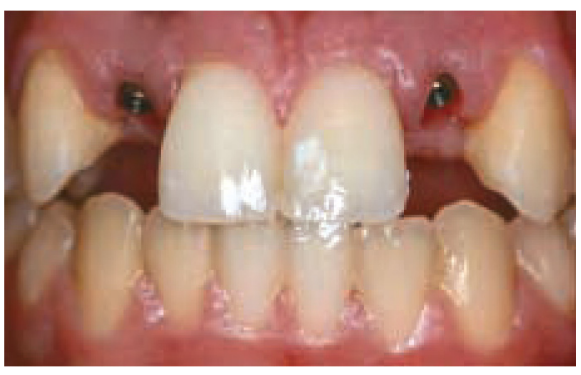

Figure 7

Placement of two Straumann NNI implants (narrow in diameter with an endosseous $3.3 \mathrm{~mm}$ body and an above bone neck of $3.5 \mathrm{~mm}$ ) to replace the congenitally absent upper lateral incisors. Dr Sophie Rozencweig of Grenoble completed the orthodontic preparatory treatment

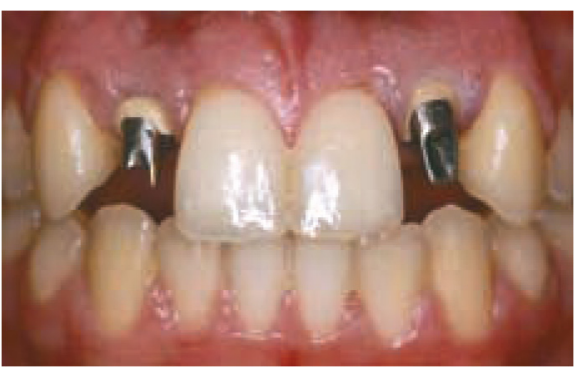

Figure 8

Placement of two post with ceramic coatings in preparation for reception of two ceramo-metallic crowns with ceramic shoulders so that as physiologic dehiscence of the gingiva proceeds no unsightly black metallic border will appear.

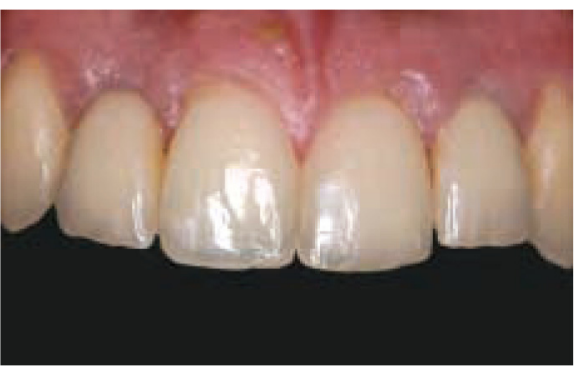

Figure 9

Crowns that Marc AndrÕ Leriche Smile Design in Beaune (Cote d'Or) fabricated have been placed. supporting gingival papillas that will open up unattractive black triangles indicative of an esthetic failure. When all these security limits are respected, practitioners will have set up a comfort zone within which they can confidently place an implant whose size is in conformity with those limits and minimal in respect to the prosthesis designed to fill it. By evaluating an agenesis site space the practitioner can thus delineate two additional danger areas around the minimal comfort zone appropriate to the implant being utilized (schema 1).

In the bucco-lingual sense ${ }^{6}$ similar reasoning applies (schema 2) and a minimal osseous wall of $2 \mathrm{~mm}$ is 

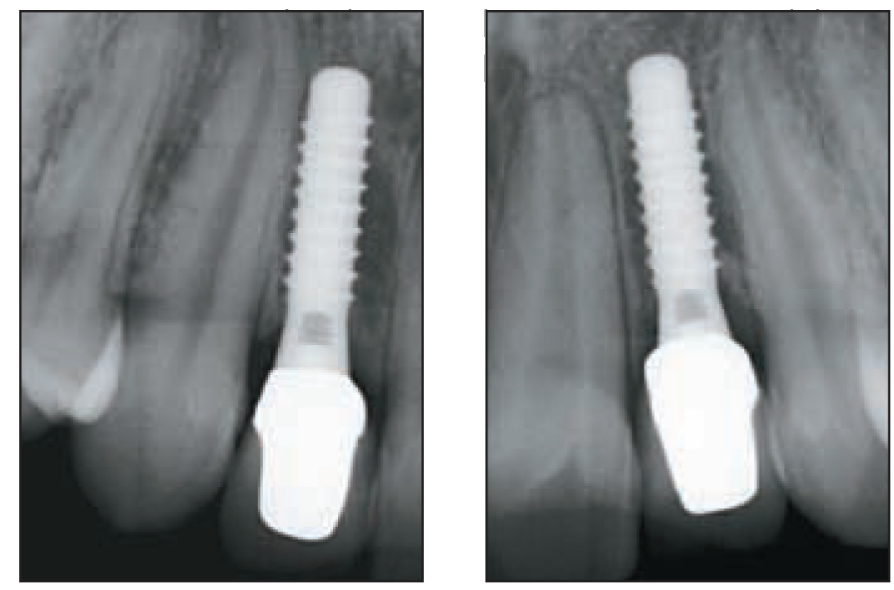

Figures 10 and 11

Radiographs of the two implants in place with the post and the ceramo-metallic crown in place. Illustration of an osseous column of a minimum of $6.5 \mathrm{~mm}$ in width. If only a lesser volume of bone were available, an implant would be contra-indicated. It is worth noting that at crestal level, stable proximal bone is present at the sites of all the adjacent teeth. The stability of this bone is indispensable for the existence and the persistence of inter-dental gingival papillae.

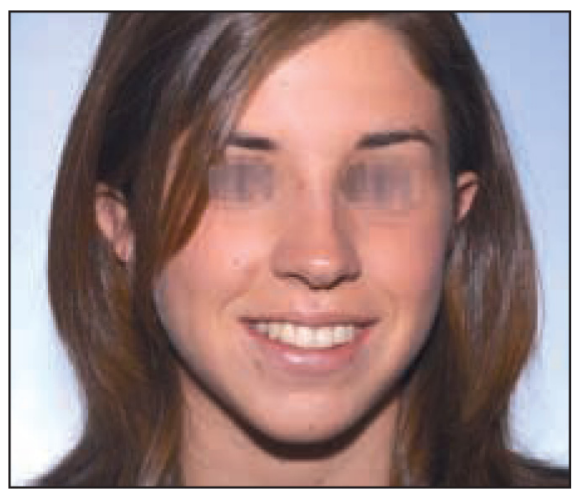

Figures 12

Esthetic integration of the restorations with the smile line.

is required to assure long term stability $^{8,16,22}$. But there is a great risk that this osseous barrier may be resorbed by a craterization stemming from the vertical situation of the implant plateform or the smooth collar of the implant, which may be of the type with a 1.5 horizontal projection. In a fashion similar to what happens around natural teeth ${ }^{21}$ with thin periodontium, there can also be resorption of slim buccal walls of less than a $\mathrm{mm}$, because of lack of sufficient inherent vascularity and insufficient resistant strength against the mechanical constraints associated with an implant. This impact concentrates essentially on the crestal zone so practitioners must be sure at least $2 \mathrm{~mm}$ of bone is present between the implant and lines representing the walls surrounding adjacent teeth (fig. 13 to 19). If the implant is placed too close to this barrier line in disrespect for the minimal osseous thickness, bone resorption and gingival recession similar to what afflicts natural teeth with fine periodontal covering during orthodontic treatment will occur. As a result, the implant emergence profile will be too apical (fig. 20). But, if on the contrary, the implant is placed too far palatally the result will be an overly coronal projection of the collar by a practically horizontal emergence angle incompatible with the access required for good oral hygiene ${ }^{8}$. Implantologists must respect these parameters scru- 
A minimal distance of 1.5 to $2 \mathrm{~mm}$ between the implant and the adjacent natural tooth.

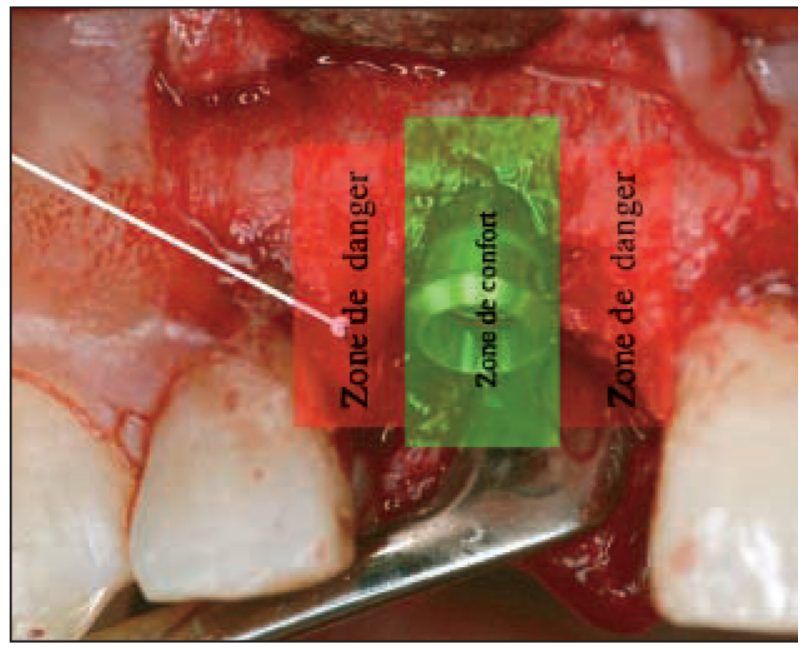

Scheme 1

Delineation of $1.5 \mathrm{~mm}$ lateral areas as danger zones into which the neck of the implant must not intrude because that might set off bone resorption. The adjacent natural teeth lie at the outer limits of these areas. The implant's intrusion into them would cause vertical bone loss along the natural root. We can speak of a horizontal projection of the "crater of resorption."

The distance $D=2 \mathrm{~mm}+$ the arc of the implant at the interior of the line tangent to the arch curvature formed by the buccal surfaces of the adjacent teeth.

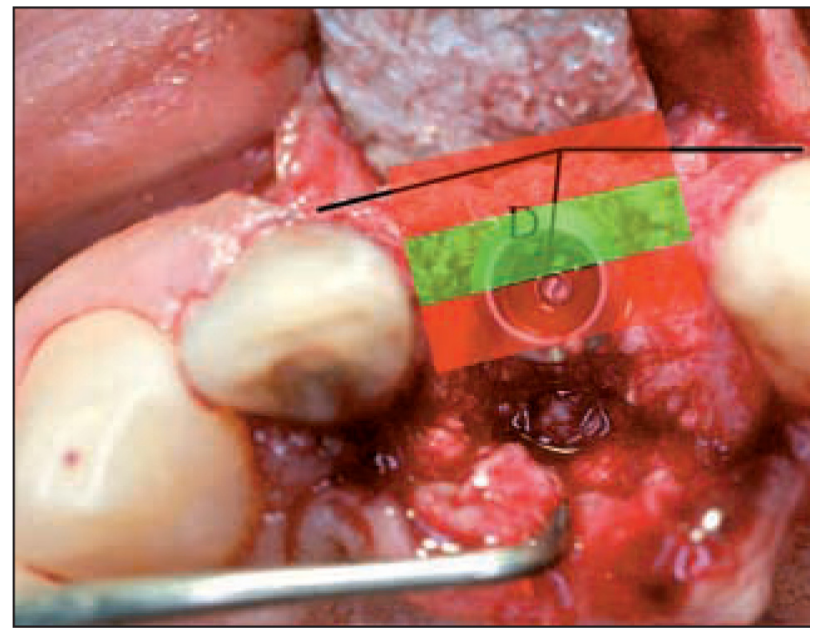

Scheme 2

Delineation of a buccal projection of the osseous wall, whose profile must resemble those of adjacent osseous walls. The neck of the implant must be located $2 \mathrm{~mm}$ behind this demarcation. If this security zone is insufficient, there will be bone resorption. The practitioner may use bone regeneration techniques to reconstruct this profile horizontally and thus re-create the indispensable $2 \mathrm{~mm}$ thickness required for long-term stability of the buccal periodontium and, accordingly, the profile of emergence.

pulously. This means that in placing implants practitioners are guided by an ideal crestal profile according to the one seen in adjacent teeth and not by the condition of the edentulous zone. If osseous thickness is less than 2 

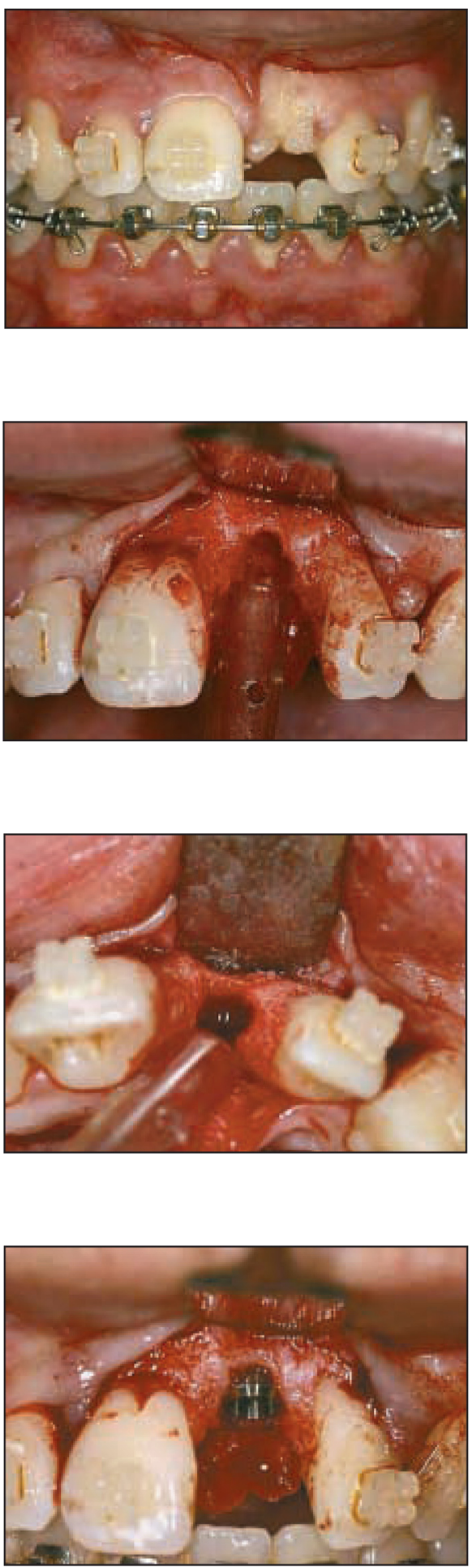

Figure 13

The upper left central incisor is congenitally absent. The Mauchamp amd Rocca orthodontic office Grenoble did the orthodontic treatment.

Figure 14

When teeth are congenitally absent the crest of bone at their sites is not festooned, which results in an excess of osseous material in the site of the missing tooth. In treatment, it is often neccessary for the surgeon trim this excess being careful, of course to work within the limit of preserving 1.5 $\mathrm{mm}$ of surrounding bone and to a depth consistent with the bone collar of the contra-laterla tooth, in this case the upper right central incisor.

Figure 15

Occlusal view of the site prepared for a straumann RN 4.1 implant collar. It is important to note that the two osseous columns provide at least the minimum 1.5 amount of proximal bone and that there a $2 \mathrm{~mm}$ osseous wall, all of which guarantees long tyerm bone stability. The depression remaining in the crestal bonem a tesult of the ageneisis, will be filled wityh embedded connective tissue in accordance with eh treatment protocol of Garber and Belser ${ }^{9}$ and following tyhe technique described by Langer ${ }^{17}$.

\section{Figure 16}

Buccal view to complete the three-dimensional analysis of the implant's positioning. Note that respecting the above crest positioning buccally has required below crest positioning proximally and, therefore, an eventual craterization of bone on a projection of $1.5 \mathrm{~mm}$. Also note the vertical positioning which in the case of above crest Straumann implants is located between $1.5 \mathrm{~mm}$ and $2 \mathrm{~mm}$ as a function of the periodontal phenotype. 

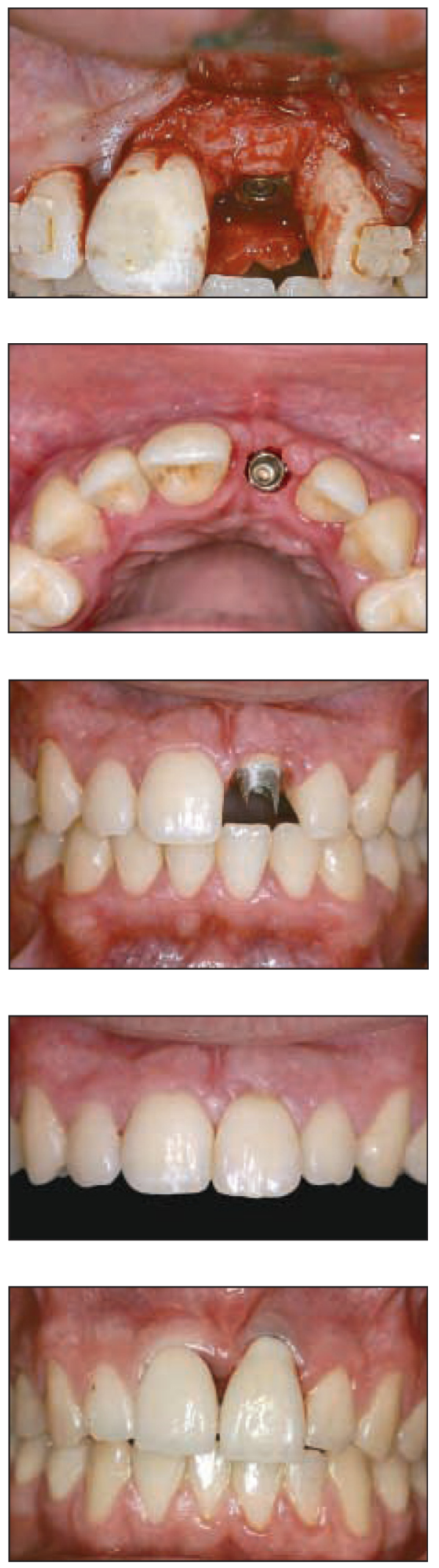

Figure 17

The connective tissue raised in the palate and partially positioned on the neck of the implant and the covering implant screw to correct the slight horizontal depression.

\section{Figure 18}

Occlusal view of healing after two months. The prosthetic phase can now begin. Note the alignment of the gingival profile of the upper left central in relation the upper right central and the fibrous quality of the gingiva despite the home care of the patient that has remained mediocre despite our best repeated motivational efforts!

\section{Figure 19}

The prosthetic post in place was cast and a ceramic cover added to its base to receive the ceramic shoulder of the ceramo-metallic crown. The casting with its ceramic base will allow the circular form of the implant collar to assume the anatomical configuration of a natural central incisor at the level of the gingiva.

\section{Figure 20}

Final result after one year. Fabrication by Marc-André Leriche - Smile Design - Beaune (Côte d'Or) laboratory.

\section{Figure 21}

The consequences of failure to respect the parameter of a $2 \mathrm{~mm}$ osseous wall derived from the positioning of the neck of an implant too far buccally. The esthetic flaw of an overly apical placement of the neck of the implant next to a loss of proximal bone and the resultant loss of the mesial gingival papilla is evident. 


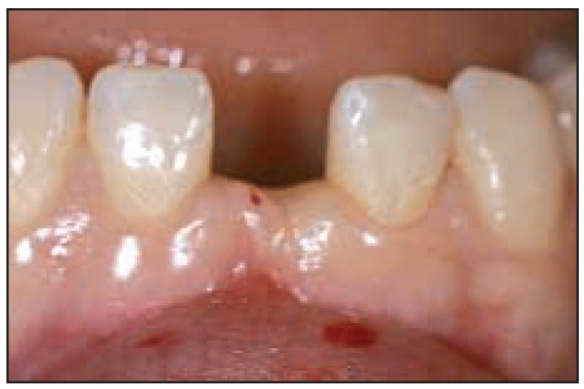

Figure 22

Space for a replacement central incisor in the site where the mandibular central incisors were congenitally absent has been retrieved by orthodontic treatment performed at the Mauchamp and Rocca Grenoble orthodontic office.

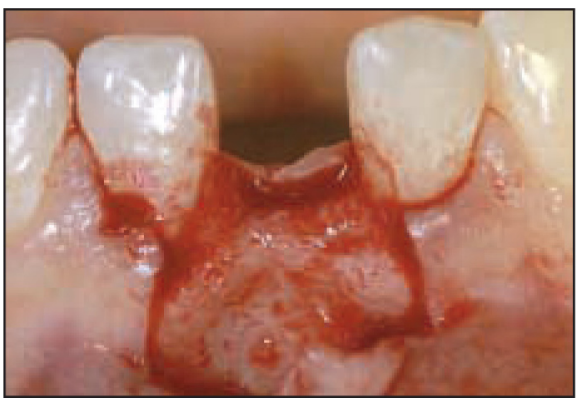

Figure 23

The characteristic osseous appearance at a site of agenesis shows the presence of a vertical excess of bone because there has been no scalloping effect. If the practitioner does not festoon the bone at the time of implant placement, the collar of the implant will lie too far in a coronal direction and the crown will not be big enough to have a satisfactory appearance. The second characteristic of these sites appears as a horizontal depression of bone caused by the absence of a root. However, the amount of proximal bone surrounding the adjacent teeth constitutes a good bone architecture for a GBR procedure with the presence of lateral osseous walls.

$\mathrm{mm}$ buccally, dentists can employ guided bone regeneration techniques to assure the kind of periodontal support needed for the long term stability of orthodontically assisted implantoprosthetic rehabilitation. Today's techniques for restoring bone before and during placement of implants are so reliable that insufficient existing osseous structure is not an inflexible barrier in selecting suitable sites for restoration $4,5,7,9,11,15,18,22$. The necessary condition, therefore, for obtaining primary stability for implants is its placement in a sufficient volume of bone in the optimal prosthetic axis. It is imperative that primary stability be achieved for the process of osteointegration to begin. Without it, a fibrous reaction will proceed that will cause the implant to fail and require its removal (fig. 22 to 33). From the beginning of orthodontic therapy the implantologist member of the multidisciplinary team should be evaluating the necessity of a pre-implant bone graft. One indication that a graft will be needed is a crestal formation in the edentulous area one third lower than the osseous crests around adjacent teeth. If the lack of bone is less serious and the configuration of the agenesis crest is favorable the surgeon member of the team can consider using bone regeneration techniques ${ }^{4,5,11,18,22}$. But here, too, it is the responsibility of the implantologist make the final decision, one that might influence what modality the patient finally agrees to for replacement of the missing tooth.

In the vertical sense (schema 3 ) the position of the neck of the implant or the zone of the prosthetic connector 

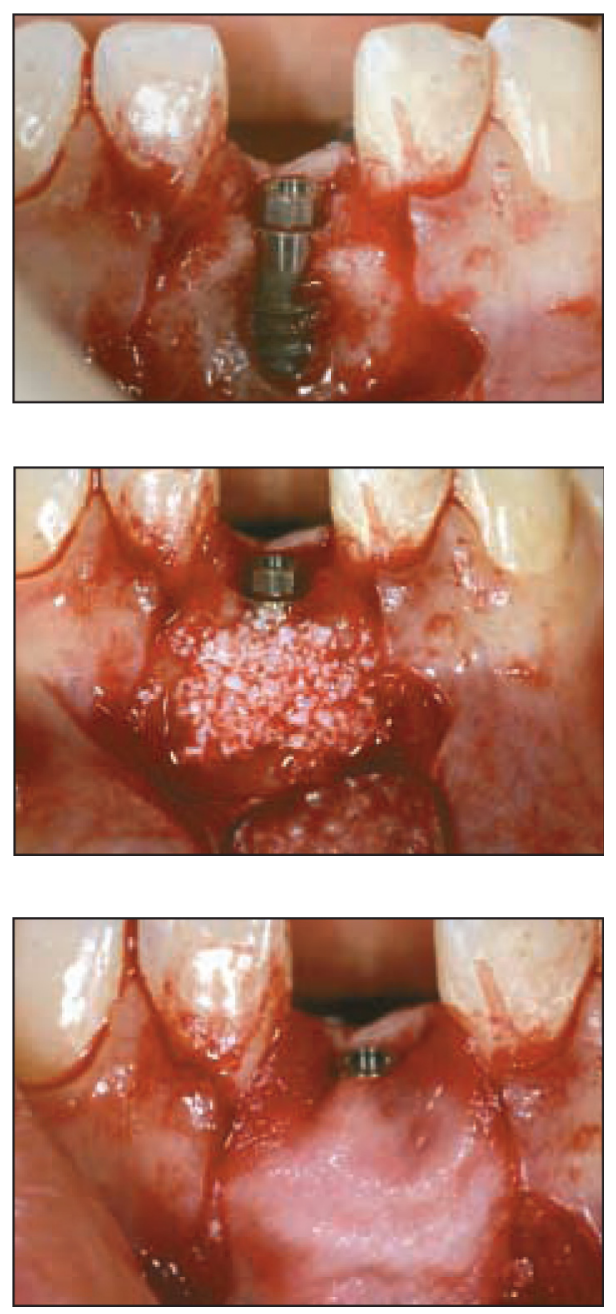

Figure 24

A Straumann NNI implant $3.3 \mathrm{~mm}$ in diameter at the bone level and $3.5 \mathrm{~mm}$ in diameter at the neck, is positioned in accordance with the principal of optimal prosthetic axis with respect for the $1.5 \mathrm{~mm}$ osseous columns. The axis required because of a lack of horizontal bone cauied a buccal fenestration that will be corected by a GBR procedure with 3 wall default thus quite well adapted to the echnique. The vertical positioning leads he level of connection to 2 $\mathrm{mm}$ from the gingival border of the adjacent tooth. This, accordingly, illustrates the tridimensional positioning of the implant.

\section{Figure 25}

Covering of the fenestration by autogenous bone covered with bovine hydroxylapatite (Bio-Oss Gestlich Pharma) rehydrated with blood in order to restore orrect bone volume in the buccal wall.

\section{Figure 26}

Covering of this graft with a collagenous resorbable membrane (BioGide Gestlich Pharma). Note the placement of a $4 \mathrm{~mm}$ healing cap in the implant so that hearing tissues will. Become obtrusive follo- wing the procedure described by Hammerle ${ }^{11}$. will vary according to the type of implant utilized. Two designs are currently in use, one with a supracrestal neck, the other with neck at the level of the crest. The first will have a neck that is located $1.5 \mathrm{~mm}$ apical to the line of the cementoenamel junction ${ }^{1,12}$. The design of implants that lie at the crest will have necks 3 to $4 \mathrm{~mm}$ apical to the line of the cemento-enamel junction $^{7,9,10,14,16}$. In an overly coronal situation there will be the esthetic risk of the the exposure of the abutment- implant interface. Conversely, an overly apical positioning will create an unstable periodontal environment because it will create a sulcus more than $4 \mathrm{~mm}$ deep, making it a potential periodontal pocket ${ }^{10,12}$. The proper location for the osseous crest should be no more than 4 to $5 \mathrm{~mm}$ from a line passing through the gingival border around the replacement tooth the way it would have with the contra-lateral tooth. If this is not achieved, practitioners should consider a bone graft set under the unsupported soft tis- 

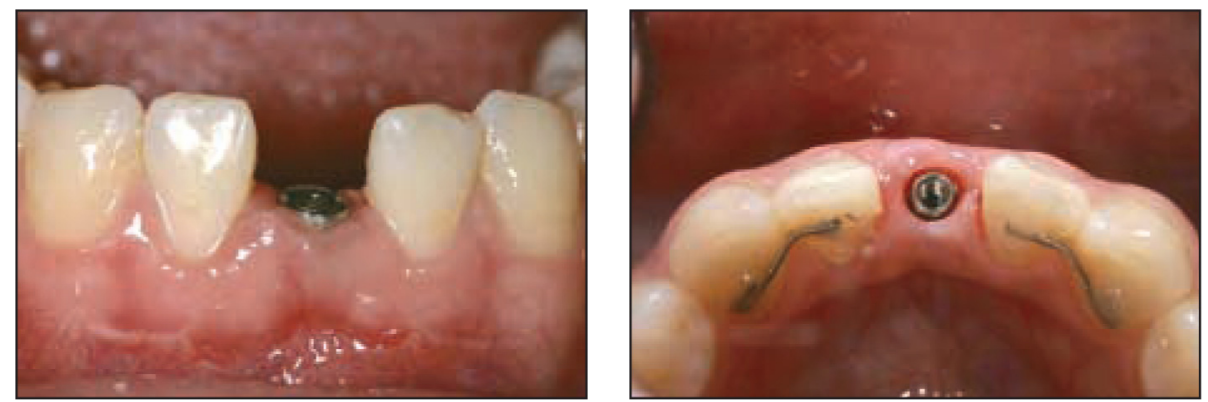

Figures 27 and 28

Situation after 2 months. Note the excess of vertical soft tissue to be guided in an apical direction by the prosthesis. Also note the amount of buccal tissue gained so that a satisfactory alignment with adja-cent profiles has been obtained.
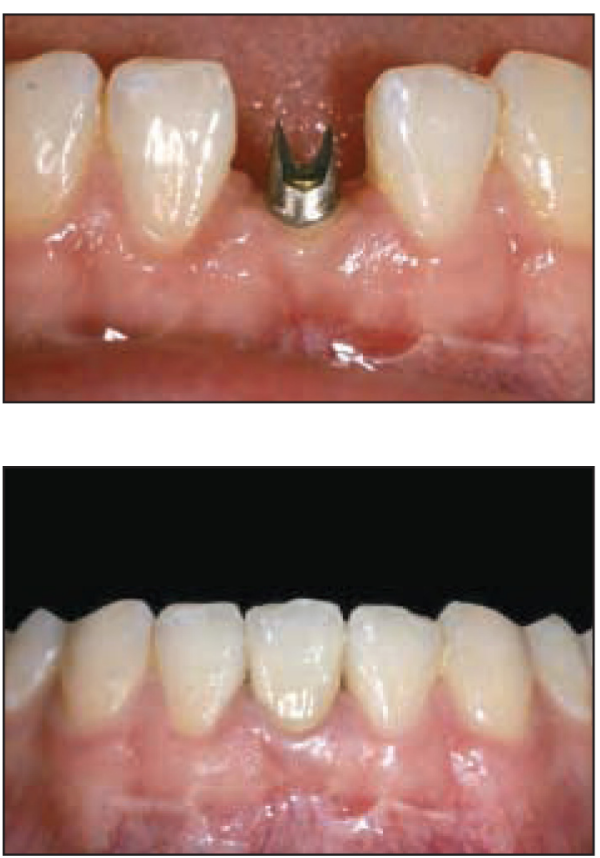

Figure 29

Cast post with ceramic base to reduce the anatomic volume at the gingival emergence of the implant with respect to its flat $3.5 \mathrm{~mm}$ circularform.

\section{Figure 30}

Placement of the ceramo-metallic crown with a ceramic shoulder. Note the apical gingival constraint designed to align the necks. The partial presence of papillae proximally (Jemt Class $1 I^{13}$ ). In response to the underlying osseous architecture the recovery of the papillae will take about 6 months.
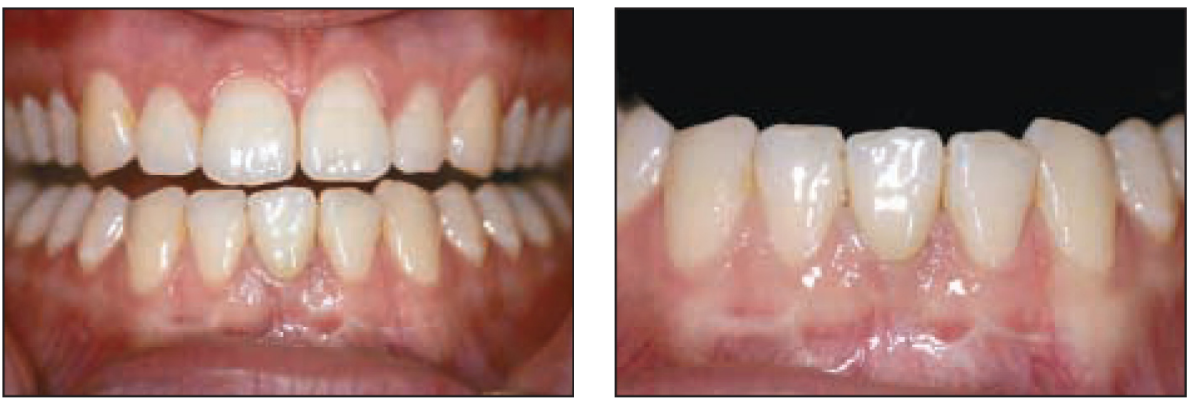

Figures 31 and 32

The stable situation after three years showing the presence of full volume gingival papillae. 


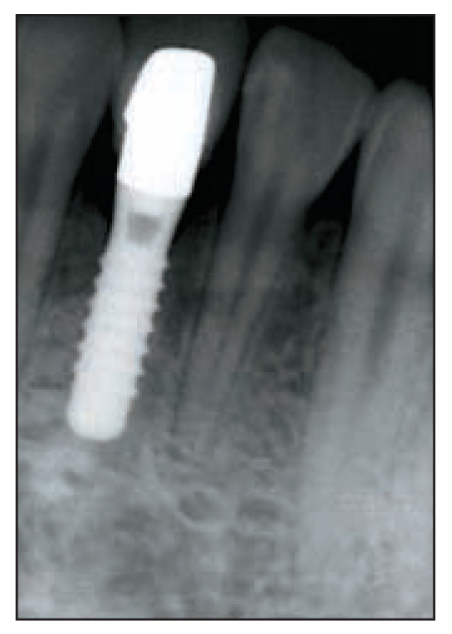

Figure 33

Radiological confirmation of the periodontal stability.

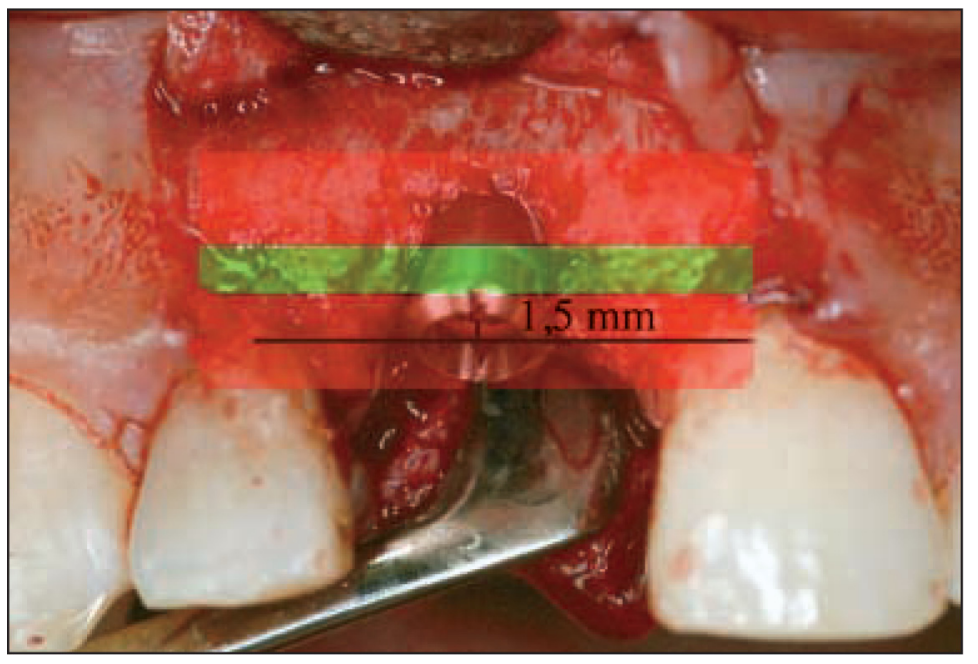

\section{Scheme 3}

The vertical positioning of an implant is dictated by the possibilities of its biological integration and the implant design. For implants above crestal bone, the neck is located at 1.5 to $2 \mathrm{~mm}$ apical to a line passing along the gingival border of the tooth symmetrical to the one being replaced. For implants at the level of the crest of bone, the neck is located 3 to $4 \mathrm{~mm}$ apical to this line. Placements lower than that may encourage pocket formation and, accordingly, risk of bacterial invasion. In such positioning an esthetic default may result.

sues that would be in an unstable condition. Below these stated values, the osseous crest should be surgically scalloped to locate it more apically with regard to the neck of the implant.

\section{5 - A LISTING OF REQUIREMENTS AND CONSEQUENCES ASSOCIATED WITH THEM}

The management of the profile of emergence of the over-all restoration requires a very precise mesio-distal and bucco-lingual positioning with each other of the body of the implant and its neck adapted to the tooth 


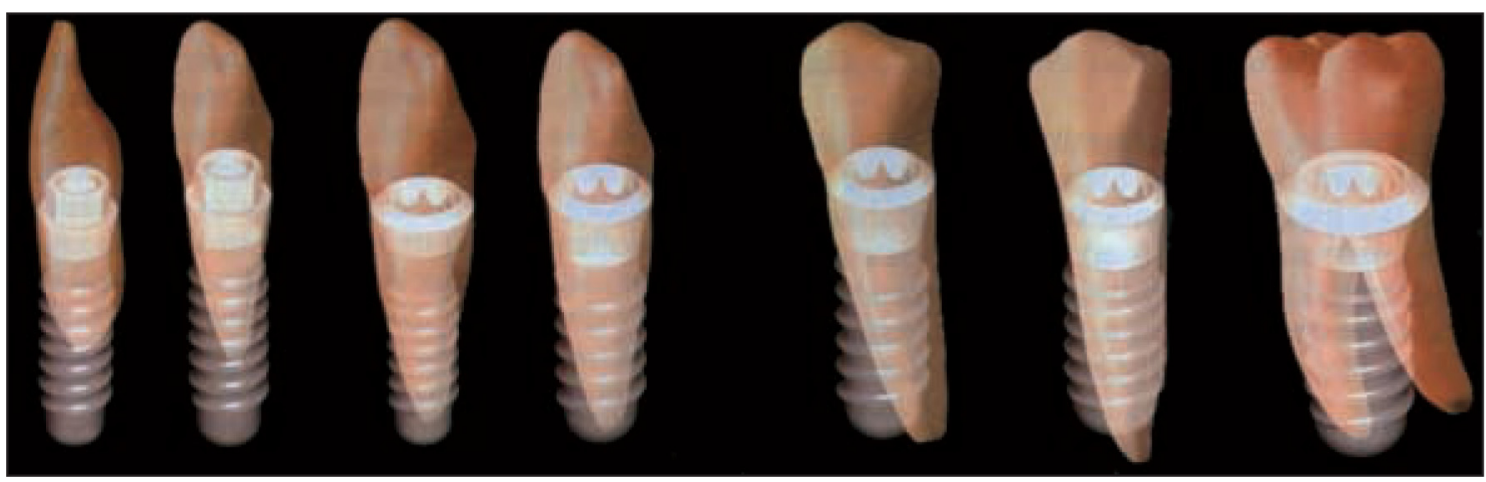

Scheme 4

Management of the profile of emergence by selection of the implant necks. Schema furnished by ITI.

being replaced (schema 4). The apicocoronal positioning will be controlled by the biological and periodontal integration that will produce a minimal sulcus depth, between 2 to $4 \mathrm{~mm}$, in harmony with the design of the implant. Agenesis sites very rarely have inadequate vertical bone levels. But not infrequently an absence of festooning causes an excess of osseous height that an oral surgeon will have to remedy by reshaping the crest so that the emergence profile of the implant will not be too coronal.

The periodontal, biological and prosthetic data allow us to define the minimal amount of bone required for the implant therapy. These dimensions will depend on the size of the implant, which itself will be based on the size of the missing tooth to be restore. There will have to be a correlation between the size of the implant platform and management of the emergence profile so that gingivally it will conform to the replacement tooth.

The catalogues of most implant systems display a range of implants including narrow, standard, and large. The narrow are usually 3.3 to $3.5 \mathrm{~mm}$ in diameter that would require a minimum of $6.5 \mathrm{~mm}$ of space for their reception. To accept a standard implant 4 to $4.5 \mathrm{~mm}$ in diameter 7.5 to $8 \mathrm{~mm}$ of space would have to be avai lable.

We can accordingly construct a chart (table I) containing two entries, the mesio-distal bone required for the replacement of the various missing teeth.

Bucco-lingually, it is important to establish a minimal amount of osseous material needed for a successful implant below which it would necessary to place a pre-implant graft while not ruling out the possibility adding another graft at the time of implant placement. As a general rule, if the horizontal loss of bone does not exceed 2 to $3 \mathrm{~mm}$, bone management may consist to a guided bone regeneration at the time of the implant placement. If, however, a shortage of available bone is greater than $4 \mathrm{~mm}$, a pre-implant bone graft will be necessary in order to assure a future alignment of the emergence profile 
Table 1

Regression summaries for effects of speeding on TAS outcome variables.

\begin{tabular}{|l|c|c|c|c|}
\hline Teeth & Dimension MD & Diameter implant & Osseous space MD & Prosthetic space \\
\hline Central incisor MAX & $9(10,3$ to 8$)$ & 4 & $7(8$ to 9$)$ & adjacent \\
\hline Lateral incisor MAX & $6,9(8,2$ to 5$)$ & 3,3 & $6,5(6$ to 7$)$ & contra-lateral \\
\hline Canine MAX & $7,7(8,3$ to 6,8$)$ & 4 & $7(8$ to 9$)$ & contra-lateral \\
\hline Premolars MAX & $7(8,5$ to 6,3$)$ & 4 & $7(8$ to 9$)$ & contra-lateral \\
\hline Molar MAX & 10,9 & 5 & $8(9$ to 10$)$ & contra-lateral \\
\hline Incisor MAND & 5 to 7 & 3,3 & $6,5(6$ to 7$)$ & contra-lateral \\
\hline Canine MAND & $6,7(7,1$ to 5,9$)$ & 4 & $7(8$ to 9$)$ & contra-lateral \\
\hline Premolars MAND & $7(8,5$ to 6,3$)$ & 4 & $7(8$ to 9$)$ & contra-lateral \\
\hline Molar MAND & $11,8(10$ to 13$)$ & 5 & $8(9$ to 10$)$ & contra-lateral \\
\hline
\end{tabular}

MD: mesio distal - MAX: maxillary MAND: mandibular.

of the prosthetic tooth with the adjacent natural teeth. Implantologists should make the final decision based upon the available data and their standards of treatment.

Vertically, it is vital that the bone crest will allow for correct positioning of the implant platform. If the crest is too low, the treatment team must reconsider the indication for an implant placement because for a single implant unit the possibilities of a bone graft in a coronal direction are quite limited. The option of using a bridge, after the ridge has been prepared with a soft tissue procedure, might be preferable $^{16,17}$. In our experience, this problem of vertical bone deficit occurs more frequently in orthodontic treatment of adults than it does in therapy for adolescents where the sites of agenesis almost never present serious vertical osseous problems that would complicate placement of implants.

It should be clearly understood that the effective dimensions for bone at the level of ridge crest apply with equal force throughout the length of the implant. This means that the column of bone should be considered in all of its three dimensional aspects with absence of any invasion of the essential implant space from divergent roots of neighboring natural teeth. Implant lengths vary from 10 to $14 \mathrm{~mm}$ depending on the school of thought of the individual practitioner and, of course, according to the width of the implant. Decisions should be made not solely on the implant's length but basically on its total surface area that will be based on three parameters: length, diameter, and the roughness of the surface. 
The treatment team should estimate the space available for an implant in an agenesis site by assessing three dimensions. They should be persuaded that the site can be prepared to receive an implant that will allow for placement of an esthetically satisfactory restoration tooth, that the available bone will allow the neck of the prosthetic unit to be set in a position harmonizing with the gingival border in a fashion that matches the contra-lateral tooth, and that there will be sufficient proximal and buccal bone to assure the long term survival of a healthy and stable periodontium. Practitioners should bear in mind that the volume of bone is important both in the anterior and posterior area of the arch. What we call esthetic volume in the anterior area should not drive us to forget that an adequate bone volume is essential in the so called non esthetic zone too, for a good oral hygiene access.

A well-placed implant will succeed in integrating biologically with its environment thus assuring its longevity. Crucial factors in this favorable result are a stable periodontium and a healthy maintenance of the original amount of supporting bone.

To achieve this, coordination between all members of the inter-disciplinary team is essential. The orthodontist must be thoroughly familiar with all aspects of the proposed site and keep ultimate objectives well in mind throughout treatment. Before band removal, the implantologist should carefully evaluate the situation and then assume responsibility for the next phase of therapy in accordance with three basic principles:

- reconstruct, insofar as is technically possible, whatever needed elements are missing at the site;

- not to lose what one has;

- conserve over time all received and reconstructed elements in the treatment site.

In the light of these imperatives, it will be interesting to follow the developments in implant technology and the improvements they will help us incorporate in our practices. We shall be especially attentive to research in the creation of additives to implant surface that will increase osteointegration capabilities. Another desirable improvement would be the capacity to correct defects in amount and quality of bone.

From a technical point of view, the introduction of new alloys of titanium, some of which are already in the testing stage, will improve the mechanical characteristics of implants and increase the mechanical resistance of prosthetic connectors of small size implants thereby increasing the scope of indications for their placement.

\section{REFERENCES}

1. Belser UC, Buser D, Hammerle C, Jung R, Martin W, Morton D, Schmid B. ITI Treatment Guide Volume 1 - Implant therapy in the esthetic zone: single tooth replacements. Berlin : Quintessence Publishing Co Ltd, 2006. 
2. Belser UC, Buser D, Hess D, Schmid B, Bernard JP, Lang NP. Aesthetic implant restorations in partially edentuous patients - a critical appraisal. Periodontology 2000 (1998);17:132-50.

3. Borghetti A, Monnet-Corti V. Chirurgie plastique parodontale. Paris: èditions CDP, 2001.

4. Buser D, Bragger U, Lang NP, Nyman S. Regeneration and enlargement of jaw bone using guided tisuue regeneration. Clin Oral Implants Res 1990;1:22-32.

5. Buser D, Dahlin C, Schenk RK (eds). Guided bone regeneration in implant dentistry. Chicago: Quintessence, 1994.

6. Buser D, Martin W, Belser UC. Optimizing esthetics for implant restorations in the anterior maxilla: anatomic and surgical considerations. Int $\mathrm{J}$ Oral Maxillofac Implants 2004;19(suppl):43-61.

7. Davarpanah M, Martinez H, Celleti R, Tecucianu JF. Three stage approach to esthetic implant restoration: Emergence profil concept. Prat Aesthet Dent 2001;13:761-7.

8. Evans C, Chen ST. Esthetic outcomes of immediate implant placements. Clinical Oral Implants Research 2008;19(1):73-80.

9. Garber DA, Belser UC. Restorative-driven implant placement with restorationgenerated site development. Compend Contin Educ Dent 1995;16:796,798-802.

10. Goldberg PV, Higginbottom FL, Wilson TG. Periodontal considerations in restorative and implant therapy. Priodontology 2000-2001;25:100-9.

11. Hämmerle $\mathrm{CH}$, Lang NP. Single stage surgery combining transmucosal implant placement with guided bone regeneration and bioresorbable materials. Clin Oral Implants Res 2001 Feb;12(1):9-18.

12. Hermann JS, Buser D, Schenk RK, Schoolfield JD, Cochran DL. Biologic Width around one- and two-piece titanium implants. A histometric evaluation of unloaded nonsubmerged and submerged implants in the canine mandible. Clin Oral Impl Res 2001;12:559-71.

13. Jemt $\mathrm{T}$. Regeneration of gingival papillae after single-implant treatment. Int $\mathrm{J}$ Periodontics Restorative Dent 1997 Aug;17(4):326-33.

14. Kan JY, Rungcharassaeng K, Umezu K, Kois JC. Dimensions of peri-implant mucosa: an evaluation of maxillary anterior single implants in humans. J Periodontol 2003 Apr;74(4):557-62.

15. Khoury F. Antoun H. Missika P. Bone augmentation in oral implantology. Londres: Quintessence Publishing Co Ltd, 2007.

16. Kois JC. Predictable single tooth peri-implant esthetics: Five diagnostic keys. Compend Contin Educ Dent 2001;22:199-206.

17. Langer $B$, Calagna $L$. The subepithelial connective tissue graft. J Prosthet Dent 1980;44:363-7.

18. Lynch S, Genco RJ, Marx RE. Tissue engineering - Applications in Maxillofacial Surgery and Periodontics. Chicago : Quintessence Publishing Co Inc, 1999.

19. Meijer HJA, Stellingsma K, Meijindert L, Raghoebar GM. A new index for rating aesthetics of implant- supported single crowns and adjacent soft tissues - The Implant Crown Aesthetic Index. A pilot study on validation of a new index. Clin. Oral Impl Res 2005;16:645-9.

20. Morton D, Ganeles J. ITI treatment Guide- Loading protocols in implant dentistry. Berlin: Quintessence Publishing Co Ltd, 2008:11-7.

21. Olsson $M$, Lindhe J. Periodontal characteristics in individuals with varying forms of the upper central incisors. J Clin Periodontol 1991;18:78-82.

22. Sclar A. Soft tissue and esthetic considerations in implant dentistry. Chicago: Quintessence Plublishing Co Ltd, 2003.

23. Tarnow DP, Cho SC, Wallace SS. The effect of inter-implant distance on the height of inter implant bone crest. J Periodontol 2000;71(4):546-9. 